\title{
CULTIVO DE EMBRIÕES IMATUROS DE CITROS EM DIFERENTES CONCENTRAÇÕES DE CARVÃO ATIVADO E ÁCIDO GIBERÉLICO
}

\author{
Activated charcoal and giberellic acid concentrations on immature embryos culture
}

\author{
Edvan Alves Chagas², Moacir Pasqual ${ }^{3}$, José Darlan Ramos³, Leila Aparecida Salles Pio \\ Leonardo Ferreira Dutra ${ }^{4}$, Jairo Osvaldo Cazetta ${ }^{5}$
}

\begin{abstract}
RESUMO
Adição de carvão ativado e giberelina no meio de cultura podem proporcionar melhores condições no desenvolvimento de embriões imaturos de citros. Objetivou-se avaliar o efeito de carvão ativado e GA (ácido giberélico) no cultivo de embriões imaturos provenientes do cruzamento entre laranjeira 'Pêra Rio' x tangerineira 'Poncã'. Após 118 dias da polinização, frutos imaturos, com 3 a 4 $\mathrm{cm}$ de diâmetro, foram coletados, suas sementes removidas e tratadas com álcool (70\%) por cinco minutos, hipoclorito de sódio (2\%) por 20 minutos e, posteriormente, lavadas três vezes em água destilada e autoclavada. Em condições assépticas, os tegumentos das sementes foram separados, os embriões globulares excisados e inoculados em tubos de ensaio contendo $15 \mathrm{~mL}$ do meio MT, acrescido de carvão ativado $\left(0 ; 0,5 ; 1 ; 1,5\right.$ e $\left.2 \mathrm{~g} \mathrm{~L}^{-1}\right)$ e $\mathrm{GA}_{3}\left(0 ; 0,01 ; 0,1 ; 1\right.$ e $\left.10 \mathrm{mg} \mathrm{L}^{-1}\right)$. Após a inoculação, os embriões permaneceram por 90 dias em sala de crescimento a $27 \pm 1^{\circ} \mathrm{C}$, fotoperíodo de 16 horas e irradiância de $32 \mathrm{mmol} \mathrm{m}^{-2} \mathrm{~s}^{-1}$. Maior comprimento da parte aérea foi obtido em meio MT, acrescido de 0,1 e $1 \mathrm{mg} \mathrm{L}^{-1}$ de GA, combinado com $2 \mathrm{~g} \mathrm{~L}^{-1}$ de carvão ativado. Maior comprimento do sistema radicular, massa da matéria fresca e número de folhas de plântulas foram obtidos em meio MT, acrescido de $0,01 \mathrm{mg} \mathrm{L}^{-1} \mathrm{de} \mathrm{GA}_{3}$, na ausência de carvão ativado. A adição de carvão ativado influenciou na concentração de ácido giberélico acrescido no meio de cultura.
\end{abstract}

Termos para indexação: Citrus sinensis, Citrus reticulata, cultura de embriões.

\begin{abstract}
Activated charcoal and gibberelin provides better conditions on development of citrus immature embryos. Activated charcoal and $\mathrm{GA}_{3}$ (gibberelic acid) on 'Pêra Rio' sweet orange x 'Poncã' mandarin immature embryos culture was evaluated. After 118 dayspollination, imature fruits with 3 to $4 \mathrm{~cm}$ of diameter were collected, seeds removed and treated with alcohol (70\%) for five min., sodium hypoclorite (2\%) for $20 \mathrm{~min}$. and three times washed with distilled and autoclaved water. In aseptic conditions, the teguments were separated, the globular embryos excised and inoculated in test tubes containing $15 \mathrm{~mL}$ of the MT medium culture, added of activated charcoal $\left(0 ; 0.5 ; 1 ; 1.5\right.$ and $\left.2 \mathrm{~g} \mathrm{~L}^{-1}\right)$ and $\mathrm{GA}_{3}\left(0 ; 0.01 ; 0.1 ; 1\right.$ and $\left.10 \mathrm{mg} \mathrm{L}^{-1}\right)$. After inoculation, the embryos were maintained for 90 days in growth room at $27 \pm 1^{\circ} \mathrm{C}, 16$ hours photoperiod and $32 \mathrm{mmol} \mathrm{m}^{-2} \mathrm{~s}^{-1}$ irradiance. Higher length of the aerial part was obtained in MT medium added 0.01 and $1 \mathrm{mg} \mathrm{L}^{-1}$ of $\mathrm{GA}_{3}$ combined with $2 \mathrm{~g} \mathrm{~L}^{-1}$ of activated charcoal. Higher length of the roots system, fresh mass and number of leaves of seedlings was obtained in MT medium added $0.01 \mathrm{mg} \mathrm{L}^{-1}$ of GA 3 and activated charcoal absence. Addition of activated charcoal influenced in giberellic acid concentration added in MT medium.
\end{abstract}

Index terms: Citrus sinensis, Citrus reticulata, embryos culture.

(Recebido para publicação em 23 de abril de 2003 e aprovado em 10 de janeiro de 2005)

\section{INTRODUÇÃO}

Os métodos de melhoramento clássico, utilizados na obtenção de novos híbridos em Citrus e gêneros afins, estão limitados a problemas como apomixia, elevadas taxas de heterozigose, incompatibilidade sexual, esterilidade masculina e feminina, além de longo período de juvenilidade e disseminação de viroses (CAMERON \& FROST, 1968; SOOST \& CAMERON, 1975). A elevada taxa de poliembrionia, generalizada entre as espécies de Citrus, resulta normalmente em elevada taxa de aborto do embrião zigótico, devido à competição exercida sobre ele pelos embriões nucelares, geralmente mais vigorosos (SOOST \& CAMERON, 1975). Entretanto, esses embriões podem ser resgatados via cultivo in vitro em meio de cultura adequado (SHARMA et al., 1996).

O sucesso no resgate de embriões híbridos vai depender principalmente do estádio em que o embrião está sendo excisado e a composição do meio no qual está sendo posto a germinar. Quanto mais jovens os embriões, mais difícil é o cultivo in vitro, devido ao seu pequeno tamanho e danos durante a excisão e, mais complexas são suas exigências nutricionais (HU \& FERREIRA, 1998). Assim, definir o meio de cultura que possa sustentar o crescimento e desenvolvimento de embriões imaturos se constitui no aspecto mais importante da cultura de embriões (PASQUAL et al., 2001).

\footnotetext{
1 Parte da dissertação apresentada ao curso de Pós-Graduação em Agronomia/Fitotecnia - UFLA

${ }_{2}^{2}$ Pesquisador Científico - Centro Avançado de Pesquisa Tecnológica do Agronegócio de Frutas (Centro APTA-FRUTAS/IAC) - Av. Luis Pereira dos Santos, 1500 - 13.214-820 - Jundiaí, SP - echagas@iac.sp.gov.br

${ }^{3}$ Departamento de Agricultura - Universidade Federal de Lavras/UFLA - Cx. P. - 3037 - 37200-000 - Lavras, MG - mpasqual@ufla.br

${ }^{4}$ Dr. Pesquisador da Embrapa Florestas - Colombo, PR - leodutra@cnpf.embrapa.br

${ }^{5}$ Professor Adjunto - Departamento de Tecnologia - Universidade Estadual Paulista/UNESP - Via de Acesso Prof. Paulo Donato Castellane, $\mathrm{s} / \mathrm{n}$ 14.884-900 - Jaboticabal,SP - cazetta@fcav.unesp.br
} 
Em razão disso, têm sido realizados importantes trabalhos com o objetivo de elucidar os efeitos de diversos fatores no cultivo in vitro de embriões de citros, dentre eles pH, ágar, concentrações do meio MS, sacarose, ácido giberélico e carvão ativado, fotoperíodo (PASQUAL et al., 2002a, b, 2003; RIBEIRO et al., 1997, 1998, 1999a, b, 2000), concentração ótima de macro e micronutrientes, vitaminas, sacarose e misturas complexas do meio de cultura MT (CHAGAS et al., 2002a, b; MORAIS, 1997), além de estudos de identificação dos estádios de desenvolvimento embrionário (CHAGAS et al., 2002c; RIBEIRO et al., 1999b).

As giberelinas participam de muitas atividades fisiológicas importantes nos vegetais, tendo efeito no crescimento, especialmente no alongamento celular (CROCOMO \& CABRAL, 1988). Um dos principais efeitos e aplicações das giberelinas em cultura de tecidos é o alongamento das brotações durante a multiplicação ou, antes, do enraizamento. Outros benefícios desse regulador de crescimento são os de promover o desenvolvimento ontogênico natural dos embriões sem primórdio radicular, aqueles com primórdio e proporcionar a iniciação de uma zona radicular existente. Em alguns casos, o ácido giberélico tem sido usado para a conversão de embriões somáticos em plantas (GUERRA et al., 1998). A concentração de $1 \mathrm{mg}$ $\mathrm{L}^{-1}$ de $\mathrm{GA}_{3}$ estimulou a formação de raízes em embriões somáticos de nucelos de Citrus (BUTTON \& BORGNMAN, 1971).

O carvão ativado, por adsorver substâncias inibitórias do meio ou produtos tóxicos liberados pelos explantes, promove o crescimento de embriões, podendo ser utilizado com sucesso por diferentes culturas entre 0,2\% a 3\% (PASQUAL et al., 2001). Outra propriedade atribuída ao carvão ativado, como sendo benéfica no processo de enraizamento, diz respeito à redução da quantidade de luz que chega na região de formação de raízes. A utilização de 0,5 e 2,0 $\mathrm{g} \mathrm{L}^{-1}$ de carvão ativado em meios nutritivos estimulou o crescimento do sistema radicular e da haste caulinar de embriões de citros (RIBEIRO et al., 2000). Por outro lado, Tomaz et al. (2001) verificaram que o carvão ativado teve efeito negativo na germinação de embriões de citros de 'Seleta Vermelha'. Neste estudo, os autores observaram que o carvão ativado adsorve compostos que estão envolvidos no processo de germinação.

Objetivou-se estudar o efeito de diferentes concentrações de carvão ativado e ácido giberélico no cultivo de embriões imaturos oriundos de frutos provenientes do cruzamento controlado entre laranjeira 'Pêra Rio' x tangerineira 'Poncã'.

\section{MATERIAIS E MÉTODOS}

Utilizaram-se frutos coletados 118 dias após a polinização, com 3 a $4 \mathrm{~cm}$ do maior diâmetro transversal, provenientes de hibridação controlada entre Citrus sinensis (L.) Osbeck 'Pêra Rio' x Citrus reticulata Blanco 'Poncã'. As sementes dos frutos foram removidas e tratadas com álcool $70 \%$ por cinco minutos, hipoclorito de sódio a $2 \% \mathrm{v} / \mathrm{v}$ do produto comercial Qboa ${ }^{\circledR}$ por 20 minutos, sendo em seguida lavadas três vezes em água destilada e autoclavada.

Com auxílio de microscópio estereoscópico, bisturi e pinça, em condições assépticas, os tegumentos das sementes foram separados longitudinalmente pela região oposta à micrópila, tomando-se o cuidado de não provocar danos aos embriões. Embriões imaturos no estádio globular foram excisados e inoculados individualmente em tubos de ensaio contendo $15 \mathrm{~mL}$ de meio de cultura MT (MURASHIGE \& TUCKER, 1969), acrescido de diferentes concentrações de carvão ativado $\left(0 ; 0,5 ; 1 ; 1,5\right.$ e $\left.2 \mathrm{~g} \mathrm{~L}^{-1}\right) \mathrm{em}$ combinação com $\mathrm{GA}_{3}\left(0 ; 0,01 ; 0,1 ; 1 \mathrm{e} 10 \mathrm{mg} \mathrm{L}^{-1}\right)$. Após a inoculação, os embriões foram mantidos em sala de crescimento a $27 \pm 1^{\circ} \mathrm{C}$, fotoperíodo de 16 horas e irradiância de $32 \mathrm{mmol} \mathrm{m}^{-2} \mathrm{~s}^{-1}$. O delineamento experimental utilizado foi inteiramente casualizado, em esquema fatorial $5 \times 5$, com quatro repetições, sendo cada uma constituída por três tubos de ensaio.

Após 90 dias, as plântulas foram avaliadas com base nas seguintes variáveis:

a) comprimento da parte aérea - obtido pelo comprimento médio da parte aérea das plântulas; medido a partir do colo da planta até o ápice, com auxílio de uma régua milimétrica, expresso em centímetros;

b) comprimento do sistema radicular-obtido pelo comprimento médio das raízes; medido a partir do colo da planta até a ponta da maior raiz, expresso em centímetros;

c) massa da matéria fresca da plântula - obtida pela pesagem média das plântulas (parte aérea + sistema radicular) em balança analítica, expressa em miligramas;

d) número de folhas - obtido pela média do número de folhas emitidas pelas plântulas; fez-se a contagem do número de folhas emitidas por explante;

Após a avaliação, as plântulas foram aclimatizadas para posterior identificação de possíveis híbridos.

Para a análise estatística utilizou-se o software Sisvar (FERREIRA, 2000) e os tratamentos foram comparados mediante regressão polinomial.

Ciênc. agrotec., Lavras, v. 29, n. 6, p. 1125-1131, nov./dez., 2005 


\section{RESULTADOS E DISCUSSÃO}

Maiores comprimentos da parte aérea foram observados quando adicionaram-se 0,$1 ; 1$ e $10 \mathrm{mg} \mathrm{L}^{-1} \mathrm{de}$ $\mathrm{GA}_{3}$ associado com $2 \mathrm{~g} \mathrm{~L}^{-1}$ de carvão ativado ao meio de cultura. Quando não se adicionou giberelina, observou-se o menor valor para esta variável; indicando a essencialidade da adição do $\mathrm{GA}_{3}$ no meio de cultura para o cultivo de embrião globular. Bons resultados no comprimento da parte aérea também são observados utilizando-se $0,01 \mathrm{mg} \mathrm{L}^{-1}$ de $\mathrm{GA}_{3}$ na presença de 0,5 ou $1,5 \mathrm{~g} \mathrm{~L}^{-1}$ de carvão ativado (Figura 1).

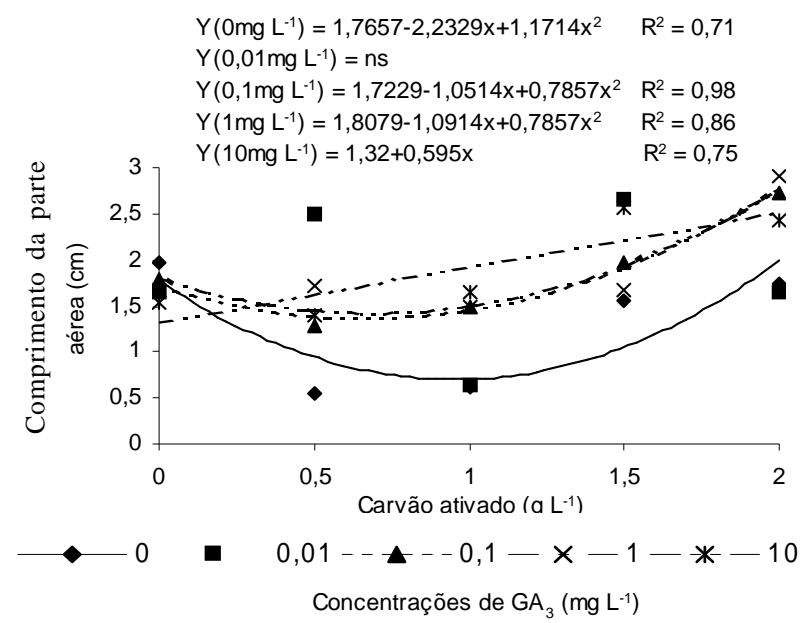

FIGURA 1 - Comprimento da parte aérea de plântulas oriundas de embriões imaturos (no estádio globular) provenientes de hibridação controlada entre laranjeira 'Pêra Rio' x tangerineira 'Poncã', cultivados em meio de cultura MT (1969) acrescido de diferentes concentrações e combinações de carvão ativado e GA. UFLA, Lavras, MG, 2002.

O efeito estimulatório da giberelina observado no comprimento da parte aérea, provavelmente, deveu-se ao fato de que, nos vegetais, esse fitorregulador participa de muitas atividades fisiológicas importantes, tendo efeito no crescimento, especialmente no alongamento caulinar (CROCOMO \& CABRAL, 1988).

O carvão ativado, devido a capacidade de adsorver substâncias tóxicas liberadas pelos próprios explantes ou impurezas de outros componentes, como sacarose e sais, pode ter contribuído para o maior comprimento da parte aérea. Efeito benéfico do carvão vegetal foi constatado, em alguns casos, em concentrações entre $0,1 \%$ e $2 \%$ (BOULAY, 1984; GRATTAPAGLIA \& MACHADO, 1998;
RICCI et al., 2002; TILQUIN, 1979). Por outro lado, o carvão ativado pode também interferir nos reguladores de crescimento acrescentados ao meio, reduzindo seu efeito. Tal comportamento foi observado no presente trabalho, uma vez que os maiores comprimentos da parte aérea foi obtido com $2 \mathrm{~g} \mathrm{~L}^{-1}$ de carvão ativado combinado com as maiores concentrações de ácido giberélico $(0,1 ; 1,0$ e $10 \mathrm{mg}$ $\mathrm{L}^{-1}$ de $\mathrm{GA}_{3}$ ) (Figura 1). Assim, evidencia-se que são necessários maiores concentrações de $\mathrm{GA}_{3}$, quando na presença de carvão ativado, para ter efeito sobre o explante.

Parthasarathy \& Parthasarathy (1993), trabalhando com embrióides de Citrus reticulata Blanco, observaram que $1 \mathrm{mg} \mathrm{L}^{-1}$ de $\mathrm{GA}_{3}$ promoveu a formação de plântulas com adequado crescimento aéreo e radicular. Ribeiro et al. (2000), trabalhando com Citrus limonia Osbeck x Poncirus trifoliata (L.) Raj, constataram boa eficiência do carvão ativado no crescimento da parte aérea quando utilizaram 0,5 e $2 \mathrm{~g} \mathrm{~L}^{-1} \mathrm{de}$ carvão ativado. Por outro lado, observaram que a concentração de $0,1 \mathrm{mg} \mathrm{L}^{-1}$ de $\mathrm{GA}_{3}$ interagiu antagonicamente em meio de cultivo contendo $2 \mathrm{~g} \mathrm{~L}^{-1}$ de carvão ativado, ao passo que a concentração de $0,01 \mathrm{mg} \mathrm{L}^{-1}$ de $\mathrm{GA}_{3}$, associada às concentrações de 0,5 até $2 \mathrm{~g} \mathrm{~L}^{-1}$, maximizou o percentual de sobrevivência dos embriões. Ricci et al. (2002) verificaram que a utilização de $0,5 \mathrm{~g} \mathrm{~L}^{-1}$ de carvão ativado também teve efeito positivo na formação de plântulas de tangerineira 'Poncã' e 'Kinow' oriundas de embriões imaturos.

Maior comprimento do sistema radicular foi obtido com a utilização de $0,01 \mathrm{mg} \mathrm{L}^{-1}$ de $\mathrm{GA}_{3}$, na ausência de carvão ativado. A não-utilização de $\mathrm{GA}_{3}$ ou a utilização de concentrações maiores que $0,01 \mathrm{mg} \mathrm{L}^{-1}$ desse fitorregulador na presença de carvão ativado não proporcionaram melhores respostas; mais inibiu o crescimento radicular (Figura 2). Esta inibição pode ser vista também, claramente, em meios de cultivo contendo concentrações mais elevadas de carvão ativado, principalmente nos tratamentos com baixa concentração de $\mathrm{GA}_{3}\left(0,01 \mathrm{mg} \mathrm{L}^{-1}\right)$.

Este resultado está de acordo com os obtidos por Pasqual et al. (1990), em laranjeira 'Natal'e com Ribeiro et al. (2000), em híbrido Poncirus trifoliata x Citrus limonia, os quais obtiveram excelentes resultados com adição de $\mathrm{GA}_{3}$ no meio de cultura, na ausência de carvão ativado. Segundo Boulay (1984), elevadas concentrações de carvão ativado podem até mesmo impedir o enraizamento. Embora Tisserat (1982) tenha constatado que a utilização de carvão ativado estimulou o enraizamento, restaurou a capacidade embriogênica in vitro das culturas velhas e diminuiu a intoxicação causada pelos fenóis, os resultados obtidos no presente trabalho não constataram tais efeitos benéficos para o crescimento radicular. 


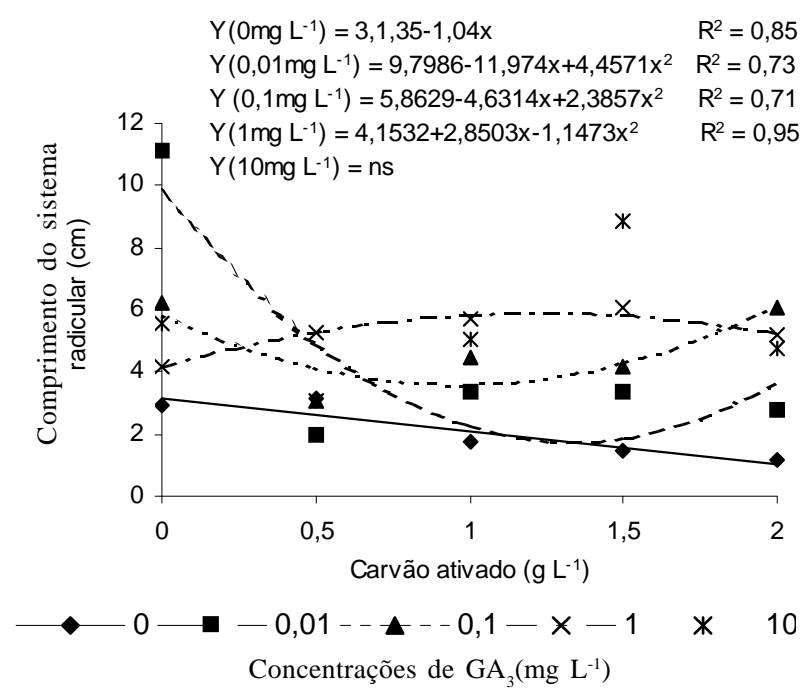

FIGURA 2 - Comprimento do sistema radicular de plântulas oriundas de embriões imaturos (no estádio globular) provenientes de hibridação controlada entre laranjeira 'Pêra Rio' x tangerineira 'Poncã', cultivados em meio de cultura MT (1969) acrescido de diferentes concentrações e combinações de carvão ativado e GA . UFLA, Lavras, MG, 2002.

Resultados semelhantes ao comportamento do comprimento do sistema radicular podem ser observados para massa fresca de plântulas (Figura 3) e número de folhas (Figura 4). Em ambas as variáveis houve redução com o aumento das concentrações de carvão ativado, sendo os maiores valores obtidos na ausência desta substância e com adição de $0,01 \mathrm{mg} \mathrm{L}^{-1}$ de GA 3 no meio de cultura.

Especialmente em relação à massa fresca de plântula, ainda pode-se ressaltar os bons resultados obtidos utilizando-se 0,5 ou $1,5 \mathrm{~g} \mathrm{~L}^{-1}$ de carvão ativado combinado com $10 \mathrm{mg} \mathrm{L}^{-1}$ de $\mathrm{GA}_{3}$ (Figura 3). Provavelmente, quando adicionou-se carvão ativado no meio de cultura, houve a necessidade de concentrações maiores de $\mathrm{GA}_{3}$ para proporcionar algum efeito estimulatório. Tais resultados indicam que este fitorregulador pode estar sendo, em parte, adsorvido pelo carvão ativado.

Em síntese, melhores resultados para comprimento do sistema radicular, massa fresca e número de plântulas foram obtidos com a utilização de $0,01 \mathrm{mg} \mathrm{L}^{-1} \mathrm{de} \mathrm{GA}_{3}$ na ausência de carvão ativado (Figuras 2, 3 e 4) ou associado com 0,5 ou $1,5 \mathrm{~g} \mathrm{~L}^{-1}$ de carvão ativado para comprimento

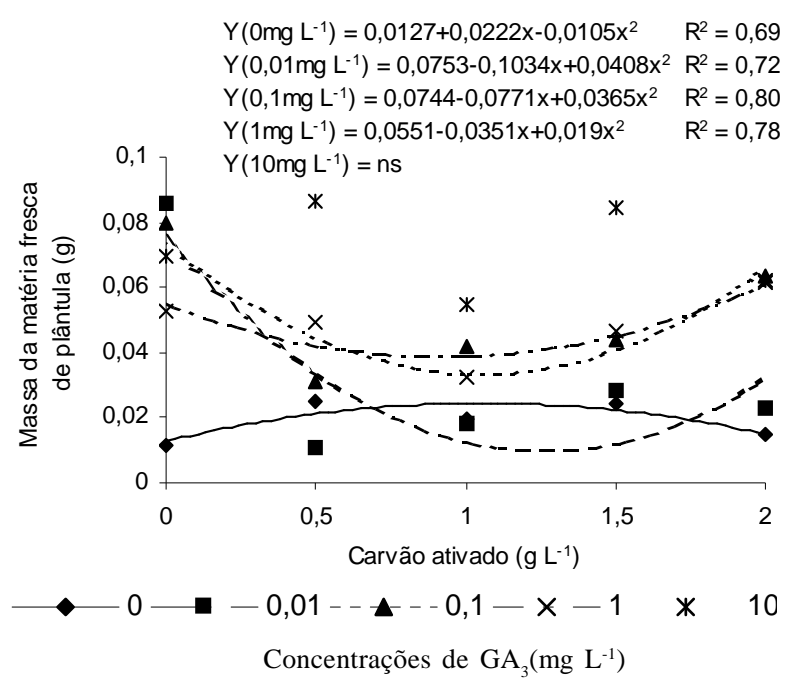

FIGURA 3 - Massa da matéria fresca de plântulas oriundas de embriões imaturos (no estádio globular) provenientes de hibridação controlada entre laranjeira 'Pêra Rio' x tangerineira 'Poncã', cultivados em meio de cultura MT (1969) acrescido de diferentes concentrações e

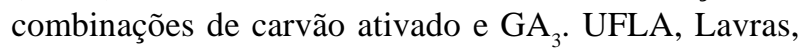
MG, 2002.

da parte aérea (Figuras 1). A baixa exigência de ácido giberélico verificada para estas variáveis pode ser explicada pelo fato de os embriões possuírem capacidade de produzir certa quantidade endógena deste fitohormônio, como foi verificado por Jimenez et al. (2001). Contudo, há necessidade de se adicionar certa quantidade de ácido giberélico no meio de cultura para promover melhor desenvolvimento de embriões (NORSTOG, 1979).

Esses resultados concordam com os obtidos por Ribeiro et al. (2000), ao observarem que a adição ao meio MS de $0,01 \mathrm{mg} \mathrm{L}^{-1}$ de $\mathrm{GA}_{3}$ favoreceu o crescimento e o desenvolvimento de embriões oriundos do cruzamento entre Citrus limonia x Poncirus trifoliata. Das et al. (2000), trabalhando com embriões zigóticos e nucelares maduros de laranjeira doce, cultivados em meio MS, observaram que a presença de $1 \mathrm{mg} \mathrm{L}^{-1}$ de $\mathrm{GA}_{3}$ induziu a formação de plântulas. Todavia, estas apresentaram crescimento lento, evidenciando que, dependendo da espécie ou variedade, concentrações elevadas de ácido giberélico não são benéficas para o desenvolvimento de embriões. Tal interpretação também foi feita por Fossard et al. (1978) e Jarvis (1986). 


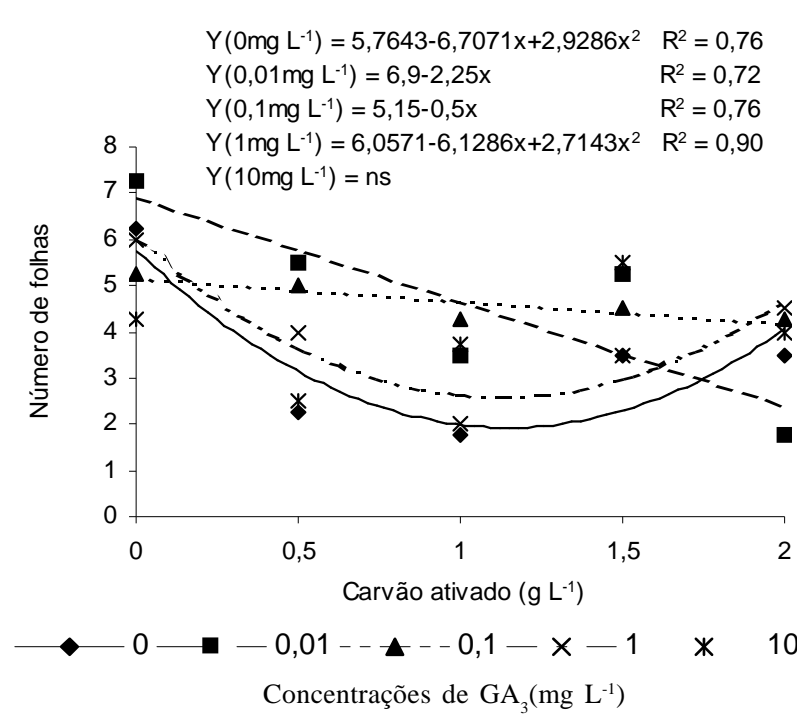

FIGURA 4 - Número de folhas de plântulas oriundas de embriões imaturos (no estádio globular) provenientes de hibridação controlada entre laranjeira 'Pêra Rio' $x$ tangerineira 'Poncã', cultivados em meio de cultura MT (1969) acrescido de diferentes concentrações e

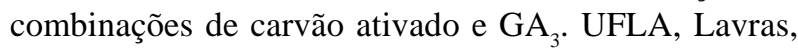
MG, 2002.

Entretanto, tais resultados discordam daqueles em que as concentrações de $0,1 \mathrm{mg} \mathrm{L}^{-1}$ (JUMIN \& NITO, 1996; PASQUAL et al., 1990; SCHOOLER, 1960), $1 \mathrm{mg} \mathrm{L}^{-1}$ (CARIMI et al., 1998; KUNITAKE et al., 1991) ou $2 \mathrm{mg} \mathrm{L}^{-1}$ (GMITTER et al., 1990; ZDRUJKOVSKAJA-RICHTER, 1981) de $\mathrm{GA}_{3}$ proporcionaram melhores resultados no cultivo in vitro de embriões.

Por outro lado, o carvão ativado, quando adicionado ao meio de cultura, possui a capacidade de adsorver substâncias tóxicas liberadas pelos explantes ou impurezas de outros componentes, como sacarose e sais, sendo benéfico, em alguns casos, em concentrações entre $0,1 \%$ e $2 \%$ (BOULAY, 1984; GRATTAPAGLIA \& MACHADO, 1998; RICCI et al., 2002; TILQUIN, 1979). Não obstante, pode também interferir nos reguladores de crescimento adicionados ao meio, reduzindo seu efeito.

Tomaz et al. (2001) observaram que o carvão influenciou negativamente na germinação de embriões de 'Seleta Vermelha', atribuindo tal efeito à possibilidade do carvão ativado adsorver compostos que estão envolvidos no processo de germinação. Os mesmos autores observaram que o número de embriões germinados de laranjeira 'Seleta Vermelha' foi $16 \%$ maior quando cultivado em meio com ausência de carvão ativado.
Contrariando esses resultados, o aumento do comprimento da parte aérea em maiores concentrações de carvão ativado pode ser atribuído ao efeito da giberelina, cuja ação mais pronunciada é o alongamento caulinar.

\section{CONCLUSÕES}

De acordo com os resultados apresentados, pôdese concluir que:

Maior comprimento da parte aérea oriundo de embriões globulares é obtido em meio MT, acrescido de 0,1 e $1 \mathrm{mg} \mathrm{L}^{-1}$ de $\mathrm{GA}_{3}$, combinado com $2 \mathrm{~g} \mathrm{~L}^{-1}$ de carvão ativado.

Maior comprimento do sistema radicular, massa da matéria fresca e número de folhas de plântulas oriundas de embriões globulares foi obtido em meio MT, acrescido de $0,01 \mathrm{mg} \mathrm{L}^{-1}$ de $\mathrm{GA}_{3}$, na ausência de carvão ativado.

A adição de carvão ativado influenciou na concentração de ácido giberélico acrescido no meio de cultura.

\section{REFERÊNCIAS BIBLIOGRÁFICAS}

BOULAY, M. Aspects pratiques de la multiplication in vitro des essences forestiers. Annales de Recherches Sylvicoles AFOCEL, Nangis, p. 7-43, 1984.

BUTTON, J.; BORGNMAN, C. H. Development of nucellar plants from unpollinated and unfertilized ovules of the Washington navel orange in vitro. Journal of South Africa Botany, [S.1.], v. 37, p. 127-134, 1971.

CAMERON, J. W.; FROST, H. B. Genetics breeding and nucellar embriony. In: REUTHER, W.; BATCHELOR, L. D.; WEBBER, H. J. (Eds.). The citrus industry. Berkeley: University of California, 1968. v. 2, p. 325-370.

CARIMI, F.; PASQUALE, F. de; PUGLIA, A. M. In vitro rescue of zigotic embryos of sour orange, Citrus aurantium L., and their detection based on RFLP analisys. Plant Breeding, Berlin, v. 117, n. 3, p. 261-266, 1998.

CHAGAS, E. A.; PASQUAL, M.; RAMOS, J. D.; DUTRA, L. F.; PEREIRA, A. R.; ARAÚJO NETO, S. E. de; MENDONÇA, V.; ARAÚJO, A. G. de. Cultivo in vitro de embriões imaturos de 'Pera Rio Tardia' x 'Poncã' em diferentes concentrações do meio MT e da sacarose. In: CONGRESSO DE PÓS-GRADUAÇÃO DA UFLA, 11., 2002, Lavras, MG. Anais... Lavras: UFLA, 2002a. CDROM. 
CHAGAS, E. A.; PASQUAL, M.; DUTRA, L. F.; JUNQUEIRA, K. P.; SILVA, A. B. da; CARDOSO, P.; FIGUEIREDO, M. A. de. Cultivo in vitro de embriões imaturos de 'Pera Rio Tardia' x 'Poncã' em diferentes concentrações de vitaminas e sacarose. In: CONGRESSO DE PÓS-GRADUAÇÃO DA UFLA, 11., 2002, Lavras, MG. Anais... Lavras: UFLA, 2002b. CD-ROM.

CHAGAS, E. A.; PASQUAL, M.; DUTRA, L. F.; RAMOS, J. D.; SILVA, A. B. da; PIO, L. A. S.; SANTOS, F. C. Cultivo in vitro de embriões imaturos de 'Pera Rio Tardia' $\mathrm{x}$ 'Poncã' em diferentes estádios de desenvolvimento e concentrações do meio MT. In: CONGRESSO DE PÓSGRADUAÇÃO DA UFLA, 11., 2002, Lavras, MG. Anais... Lavras: UFLA, 2002c. CD-ROM.

CROCOMO, O. J.; CABRAL, J. B. A biotecnologia no melhoramento de plantas tropicais. Brasília, DF: Associação Brasileira de Educação Agrícola Superior, 1988. 39 p. (Curso de Agricultura Tropical. Módulo I: O Ambiente e as Plantas Tropicais).

DAS, A.; PAUL, A. K.; CHAUDHURIS, S. Micropropagation of sweet orange Citrus sinensis Osbeck for the development of nucellat seedling. Indian Journal of Experimental Botany, New Delhi, v. 38, n. 3, p. 269-272, 2000.

FERREIRA, D. F. Análises estatísticas por meio do Sisvar para Windows versão 4.0. In: REUNIÃO ANUAL DA REGIÃO BRASILEIRA DA SOCIEDADE INTERNACIONAL DE BIOMETRIA, 45., 2000, São Carlos. Anais... São Carlos: UFSCar, 2000. p. 255-258.

FOSSARD, R. A. de et al. Tissue culture propagation of Eucalyptus ficifolia F. Muell. Combined Proceedings of the International Plant Propagators'Scoiety, [S.1.], v. 28, p. 427-435, 1978.

GMITTER, F. G.; LING, X. B.; DENG, X. X. Induction of triploid Citrus plants from endosperm calli in vitro. Theory Applied Genetics, New York, v. 80, p. 785-790, 1990.

GRATTAPAGLiA, D.; MACHADO, M. A. Micropropagação. In: TORRES, A. C.; CALDAS, L. S.; BUSO, J. A. (Eds.). Cultura de tecidos e transformações genéticas de plantas. Brasília, DF: EMBRAPA/CBAB, 1998. p. $183-260$.
GUERRA, M. P.; TORRES, A. C.; TEIXEIRA, J. B. Embriogênese somática e sementes sintéticas. In: TORRES, A. C.; CALDAS, L. S.; BUSO, J. A. (Eds.). Cultura de tecidos e transformações genéticas de plantas. Brasília, DF: EMBRAPA/CBAB, 1998. p. 533-568.

HU, C. Y.; FERREIRA, A. G. Cultura de embriões. In: TORRES, A. C.; CALDAS, L. S.; BUSO, J. A. (Eds.). Cultura de tecidos e transformação genética de plantas. Brasília, DF: EMBRAPA/CNPH/CBAB, 1998. v. 2, p. 371393.

JARVIS, B. C. Endogenous control of adventicious rooting in non-woody cuttings. In: JACKSON, M. B. New root formation in plants and cuttings. Dordrecht: Martinus Nijhoff, 1986. p. 191-222.

JIMENEZ, V. M. et al. Endogenous hormone levels in habituated nucellar Citrus callus during the initial stages of regeneration. Plant Cell Reports, Berlin, v. 20, n. 1, p. 92-100, 2001.

JUMIN, H. B.; NITO, N. Plant regeneration via somatic embryogenesis from protoplast of six plant species related to Citrus. Plant Cell Reports, Berlin, v. 15, n. 5, p. 332-336, 1996.

KUNITAKE, H.; KAGAMI, H.; MII, M. Somatic embryogenesis and plant regeneration from protoplasts of 'Satsuma' mandarin (Citrus unshiu Marc.). Scientia Horticulturae, Amsterdam, v. 47, p. 27-33, 1991.

MORAIS, L. S. Ajuste do meio de Murashige e Tucker (MT) para o cultivo in vitro de embriões imaturos de tangerina “Cleópatra". 1997. 86 f. Dissertação (Mestrado em Fitotecnia) - Universidade Federal da Bahia, Cruz das Almas, 1997.

MURASHIGE, T.; TUCKER, D. P. H. Growth factor requirement of citrus tissue culture. In: INTERNACIONAL CITRUS SYMPOSIUM, 1., 1969, Riverside. Proceedings... Riverside: University of California, 1969. v. 3, p. 11551169.

NORSTOG, K. J. Embryo culture as a tool in the study of comparative and development morphology. In: SHARP, W. R. et al. (Eds.). Plant cell and tissue culture. Columbus: Ohio State University, 1979. p. 197-202. 
PARTHASARATHY, V. A.; PARTHASARATHY, U. Effect of growth regulators on transplanted embryoids of Citrus reticulata Blanco. Annals of Plant Physiology, [S.1.], v. 7, n. 1, p. 21-24, 1993.

PASQUAL, M.; RAMOS, J. D.; DUTRA, L. F. Aplicações no melhoramento genético de plantas. 2001. 79 p. Monografia (Especialização em Cultura de Tecidos Vegetais: tecnologia e aplicações) - Universidade Federal de Lavras, Lavras, 2001.

PASQUAL, M.; RIBEIRO, V. G.; RAMOS, J. D. Influência do $\mathrm{GA}_{3}$ e do carvão ativado sobre o enraizamento in vitro de embriões de laranja "Natal". Pesquisa Agropecuária Brasileira, Brasília, v. 25, n. 10, p. 1477-1482, 1990.

PASQUAL, M.; ALVES, G. P.; DUTRA, L. F.; CHAGAS, E. A.; RIBEIRO, L. de O. Desenvolvimento in vitro de embriões imaturos de tangerineira 'Poncã' x laranjeira 'Pera' em diferentes fotoperíodos. Ciência e Agrotecnologia, Lavras, v. 27, n. 3, p. 535-540, 2003.

PASQUAL, M.; ALVES, G. P.; DUTRA, L. F.; FINOTTI, D. R.; CHAGAS, E. A. Cultivo in vitro de embriões imaturos de tangerineira 'Poncã': concentrações do meio MS e da sacarose. Revista Ceres, Viçosa, v. 49, n. 282, p. 181-189, 2002a.

PASQUAL, M.; FINOTTI, D. R.; DUTRA, L. F.; CHAGAS, E. A.; RIBEIRO, L. de O. Cultivo in vitro de embriões imaturos de tangerineira 'Poncã' em função do pH e da concentração de ágar. Revista Brasileira de Agrociência, Pelotas, v. 8, n. 3, p. 199-202, 2002 b.

RIBEIRO, V. G. et al. Influência do pH e do ágar sobre o cultivo in vitro de embriões de laranjeira 'Pêra'. Pesquisa Agropecuária Brasileira, Brasília, v. 32, p. 1147-1152, 1997.

RIBEIRO, V. G. D. et al. Cultivo in vitro de embriões de laranja 'Pêra': concentrações do meio MS e sacarose. Ciência e Agrotecnologia, Lavras, v. 22, p. 429-434, 1998.
RIBEIRO, V. G. et al. Estádios de desenvolvimento embrionário e localização do embrião zigótico em sementes de citros. Pesquisa Agropecuária Brasileira, Brasília, v. 34, p. 1327-1333, 1999a.

RIBEIRO, V. G. et al. Influência do ágar e do pH sobre o cultivo in vitro de embriões de laranja 'Natal'. Revista Ceres, Viçosa, v. 46, p. 587-595, 1999 b.

RIBEIRO, V. G. et al. Efeitos de ácido giberélico e carvão ativado no cultivo in vitro de Citrus limonia Osbeck $\mathrm{x}$ Poncirus trifoliata (L.) Raf. Pesquisa Agropecuária Brasileira, Brasília, v. 35, p. 27-30, 2000.

RICCI, A. P. et al. Somatic embryogenesis in Citrus sinensis, Citrus reticulata and $C$. nobilis x $C$. deliciosa. Scientia Agrícola, Piracicaba, v. 59, n. 1, p. 41-46, 2002.

SCHOOLER, A. B. Wild barley hybrids. Hordeum compressum x Hordeum possillum. Journal Hered., [S.1.], v. 51, p. 179-181, 1960.

SHARMA, D. R.; KAUR, R.; KUMAR, K. Embryo rescue in plants: a review. Euphytica, Wageningen, v. 89, p. 325-337, 1996.

SOOST, R. K.; CAMERON, J. W. Citrus. In: JANICK, J.; MOORE, J. N. (Eds.). Advances in fruit breeding. West Lafayette: Purdue University, 1975. p. 507-540.

TILQUIN, J. P. Plant regeneration from stem callus of Cassava. Canadian Journal Botany, Ottawa, v. 57, n. 16, p. 1761-1763, 1979.

TISSERAT, B. Factors involved in the production of plantlets from date palm callus cultures. Euphytica, Wageningen, v. 31, p. 201-214, 1982.

TOMAZ, M. L. et al. In vitro cellular and developmental biology. Plant, [S.1.], v. 37, n. 4, p. 446-452, 2001.

ZDRUJKOVSKAJA-RICHTER, A. I. Embryo cultures and development of new forms of plants. Moscow: University Moscow, 1981. Abstract. 